\title{
THE DYNAMIC RELATIONSHIP BETWEEN PERCEIVED PARENTAL SUPPORT AND ONLINE BULLYING
}

\author{
Dana BALAS TIMAR, Ph.D., \\ dana@xhouse.ro \\ Sonia IGNAT, Ph.D., \\ soniabudean@yahoo.com \\ Edgar DEMETER, Ph.D.cnd. \\ eddemeter@yahoo.com \\ Faculty of Educational Sciences, Psychology and Social Sciences, Aurel \\ Vlaicu University
}

Abstract: Bullying is defined as a hostile / exclusionary and deceptive behavior of humiliation. A child is labeled, teased, mocked in his circle of knowledge or by colleagues calling him in a certain way (referring to physical appearance or medical / family issues). The phenomenon of "bullying" is much more common than we would like to believe. It happens on school corridors, in the yard, on the streets and, unfortunately, sometimes in classrooms. Undetected on time, bullying may leave traumas and irreversible repercussions on the child's adaptability to society. Our research team has developed the project Keeping youth safe from Cyberbullying, ID 2016-3TR01-KA205-036619 under Erasmus+, that aims to deeper understand the dynamics of cyberbullying in online environments among youth, to develop educational resources for professionals involved in youth activities in order to prevent these type behaviors, to develop youth skills to protect themselves from cyberbullying and to disseminate findings among educational professionals. One of our first interests was in analyzing the relationship between online bullying incidents and perceived parental support, due to the fact that psychological protection from any kind of harassment starts from home. Our conclusion is that there is a dynamic relationship between online bullying incidents and perceived parental support. Qualitative results and bulling prevention strategies are discussed.

Key words:bullyingirreversible, repercussions, prevent,support 


\section{Introduction}

The schoolyard represents a social micro-universe in which children receive the first lessons of life outside the family. We are talking about validation, acceptance, empathy, but we are also talking about fear, shame, and rejection. In most cases, emotional negative charge from school reverbs and covers the positive emotions, ambition and inner potential of children.

Bullying is defined as a hostile / exclusionary and deceptive behavior of humiliation. A child is labeled, teased, mocked in his circle of knowledge or by colleagues calling him in a certain way (referring to physical appearance or medical / family issues). Sometimes these teasing changes into stinging or even, in some cases, physical attacks.

Bullying is a form of emotional and physical abuse that has three characteristics:

- Intentional - the aggressor intends to hurt someone;

- $\quad$ Repeated - the same person is always injured;

- The imbalance of forces - the aggressor chooses the victim who is perceived as vulnerable, weak and unable to defend himself.

The phenomenon of "bullying" is much more common than we would like to believe. It happens on school corridors, in the yard, on the streets and, unfortunately, sometimes in classrooms. Undetected on time, bullying may leave traumas and irreversible repercussions on the child's adaptability to society.

Cases of bullying involve at least one aggressor and a victim, and in some cases there are witnesses. The literature discusses about physical, verbal, sexual or psychological bullying.

Exposing a person to violence can lead to further, such as the "butterfly effect" (a small action at a certain place, at some point in time, can cause major exponentially amplified changes in other areas) bully phenomena, both from the aggressor and from the aggressed point of view.

Often, the aggressor adopts violence as the ultimate possibility of defamation and expression, being in turn abused or neglected. The most common causes of such aggressor behavior may be lack of empathy, egocentrism, pride, superficiality of human relationships, and, in particular, the exposure and assumption of similar patterns of behavior - most often the child reproduces with the fellow what he sees at home.

Thus, it is considered that those who cause "bullying" are those who do not receive enough attention, who want to stand out, act and act accordingly. Lack of affection, approval, guidance, positive feedback, lack of love, neglect, encouragement of new life styles, new ways of imposing, earning money (drugs, prostitution, gangs) are factors facilitating bullying. The need for power and domination make the victim a target, and the aggressors will physically, socially or emotionally harm others. Often, those 
who harass, have been harassed or are themselves harassed by colleagues or family.

Children or persons that are aggressors, the bullies, are actually those who unfortunately want to show that they have a good self-esteem, that they have control and are superior to others. (Flores et. al., 2013). Families where corporal punishment is often used are a "welcome" environment for the development of deviant behavior such as bullying, inappropriate to adapt to social requirements, incapable of understanding positive discipline, and adherence to rules for proper functioning. Many studies conclude that envy and resentment may represent factors that cause bullying. There is evidence that a lack of self-esteem contributes significantly to bullying, as well as anxieties or guilt. Lack of social skills, use of force and dependence on aggressive behaviors, anger, status in the belonging group, existence of such antecedents in childhood are considered risk factors. None of the less, bullying often does not necessarily imply crime or physical violence, but acts as a psychological or verbal abuse.

Norwegian psychologist Dan Olweus (1993), recognized as a pioneer and founder of the concept, considers bullying the situation in which a person is repeatedly and in time exposed to negative, physical and psychological actions by one or more people. Intentional, direct or indirect damage is created by creating a state of discomfort in various ways: offensive words, humiliations, injuries, altercations, offenses, admonestation, constraints, scorning, screams, bangs, bruises, reproaches, inappropriate touches, obstructions, harassment, etc. Disposing of personal things (notebooks, backpacks, pens, lunch packs, etc.), hair pull, sleeve, scratches, pinching, breaking of dear objects, suffocating with various objects, exclusion, imitating and laughing are other manifestations of bullying (Ross, 2009).

In his book published in 1993 (Olweus, 1993), School bullying: What do we need to know and what should we do? the author identifies the characteristics of pupils who are more susceptible to being bullies, and those most likely to be victims of bullying. Here are the general characteristics of aggressors and victims:

- Aggressors: strongly manifests the need to lead, dominate and "subjugate" other colleagues; are impulsive, easily annoyed; are provocative, do not follow the rules; are aggressive with colleagues, parents, teachers; have no remorse and ability to understand the emotions of others (empathy); have a lack of attention: during classes they draw, throw paper, sleep, comment; have a very good, sometimes exaggerated opinion of themselves: they are considered bosses, tricks, princesses etc.; instigates school absenteeism and abuses those who do not obey the "new" rule; belong to 
some dubious groups; perceive hostile actions where they do not exist, are antisocial.

- Victims: they are passive in behavior and communication, socially isolated; are cautious, sensitive, withdrawn, shy; manifest insecurity, anxiety, exacerbated sensitivity; have a low self-esteem; have little friends or not; are unable to develop social relationships; are perceived as incapable of defending themselves, of having personal views, of arguing; have different forms of disability: speech, locomotors, etc.; displays an attitude of defeat and depressive behavior; do not cope with the pressure of the group; shows that their rights do not matter, they are ignored; do not take action against acts of aggression.

\section{Research methodology}

Our research team has developed the project Keeping youth safe from Cyberbullying, ID 2016-3-TR01-KA205-036619 under Erasmus+, that aims to deeper understand the dynamics of cyberbullying in online environments among youth, to develop educational resources for professionals involved in youth activities in order to prevent these type behaviors, to develop youth skills to protect themselves from cyberbullying and to disseminate findings among educational professionals. One of our first objectives is to analyze the dynamics of online bullying incidents, starting from youth online posting behavior. In this regard, we have designed a 7 sections online questionnaire that aims to gather descriptive data, general perception about the frequency and typology of cyberbullying type incidents, perceptions about the safety of the educational environment and parental support and an auto evaluation scale centered on self-efficacy perceptions.

One of our first interests was in analyzing the relationship between online bullying incidents and perceived parental support, due to the fact that psychological from any kind of harassment starts from home.

The two items that measured youth online bullying incidents and perceived parental support were: Item 19 - Have you ever been (online) harassed/bullied at school or in your social environment? Item 47 - My parents are always ready to listen to me or help me. Our online respondents' instruction was to rate items on a 1 to 5 Likert type scale, where 1 stands for strong disagreement and 5 reflects strong agreement with the statement.

Present study aims to analyze the relationship between youth online bullying incidents and their perceived parental support. We start from the assumption that the two variables are in a dynamic relationship. In order to test our dynamical hypothesis, we have used a confirmatory factor analysis, based on multiple regression analysis for curvilinear effects, where youth online bullying incidents was the dependent variable. 
The study was conducted on a random sample of 92 participants aged $18-30$, of both sexes, $10,9 \%$ masculine and $89,1 \%$ feminine, from both rural and urban environmental origins, with qualification levels ranging from high-school $-63 \%$ - to bachelor's and master's degree $-22,8 \%$ and $14,2 \%$, respectively.

While most participants $-68.2 \%$, have between one and three years' experience with social media platforms, only $42.4 \%$, have the same amount of experience with messaging platforms and $43.9 \%$, between no experience and one-year experience with social media platforms and messaging.

\section{Results}

In order to test our hypothesis that states that between youth online bullying incidents and youth perceived parental support there is a dynamic relationship, we have used a confirmatory factor analysis, based on multiple regression analysis for curvilinear effects.

In curvilinear relationships variables grow together until they reach a certain point (positive relationship) and then one of them increases while the other decreases (negative relationship) or vice-versa. This relationship can be easily identified graphically by a Scatterplot, choosing additional two representations of the regression line: Linear and Quadratic model.

The Scatterplot diagram presented in Figure 1, demonstrates curvilinear relationship between youth online bullying incidents on the horizontal axis and youth perceived parental support, represented on the vertical axis. The sample consists of 92 youth from Arad, Romania.

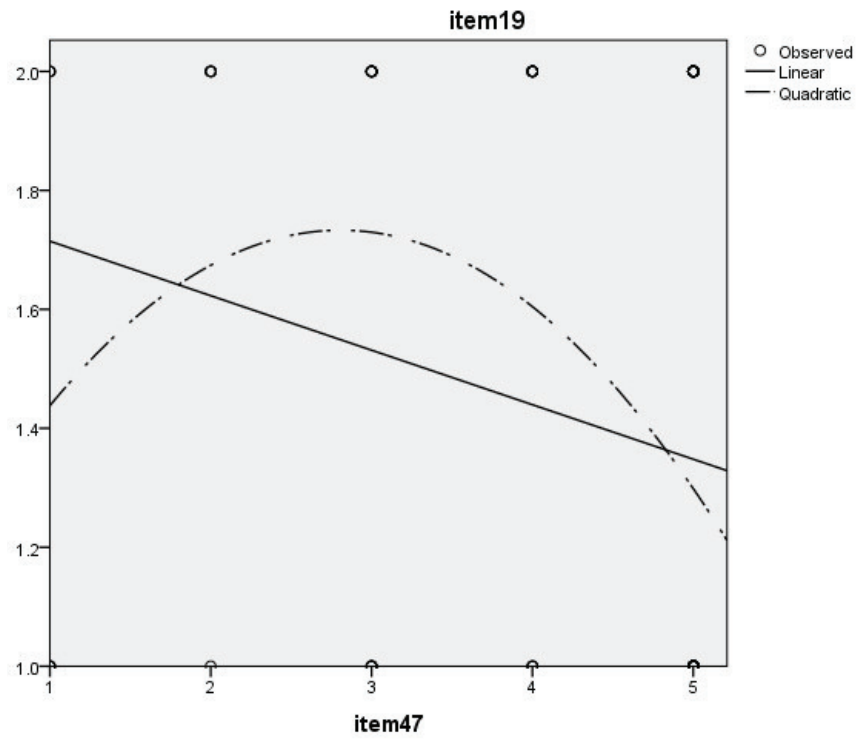

Fig. 1. The dynamic relationship between youth online bullying incidents (Item 19) and youth perceived parental support (Item 47) 
There is a very high correlation between youth online bullying incidents - Item $19(\mathrm{MD}=1,42, \mathrm{SD}=0,497)$ and youth perceived parental support - Item $47(\mathrm{MD}=4,12, \mathrm{SD}=1,290)$ of $\mathrm{r}=-0,237$ significant at a $\mathrm{p}<$ 0,05 which methodologically allows us to proceed with confirmatory factor analysis.

For curvilinear relationship testing, the present study proposes a hierarchical multiple regression analysis, the dependent variable being youth online bullying incidents, and the dependent variable in step 1 youth perceived parental support, and in step 2 squared youth perceived parental support.

Table 1 presents the fitting of the two models, linear - Model 1 and curvilinear/ quadratic - Model 2. As we can see in Model 1 the model that supposes linear relationship, youth online bullying incidents accounts for $4 \%$ of the variance in youth perceived parental support with an $F=5.318$ significant at a $\mathrm{p}<0,05$. In Model 2, the model that supposes curvilinear relationship, youth online bullying incidents accounts for $10 \%$ of the variance in youth perceived parental support with an $\mathrm{F}=6.720$ significant at a $\mathrm{p}<0,05$.

Table 1. Linear and curvilinear regression models for youth online posting selectivity depending on youth perceived parental support.

Descriptive Statistics

\begin{tabular}{|l|r|r|r|}
\hline & \multicolumn{1}{|c|}{ Mean } & Std. Deviation & \multicolumn{1}{|c|}{ N } \\
\hline item19 & 1.43 & .498 & 92 \\
item47 & 4.12 & 1.290 & 92 \\
Item47sqrt & 18.6264 & 8.66622 & 92 \\
\hline
\end{tabular}

Model Summary

\begin{tabular}{|c|c|c|c|c|c|c|c|c|c|}
\hline \multirow[t]{2}{*}{ Model } & \multirow[t]{2}{*}{$\mathrm{R}$} & \multirow{2}{*}{\begin{tabular}{|c|}
$\mathrm{R}$ \\
Square
\end{tabular}} & \multirow{2}{*}{\begin{tabular}{|c|} 
Adjusted \\
R \\
Square
\end{tabular}} & \multirow{2}{*}{$\begin{array}{c}\text { Std. } \\
\text { Error of } \\
\text { the } \\
\text { Estimate }\end{array}$} & \multicolumn{5}{|c|}{ Change Statistics } \\
\hline & & & & & $\begin{array}{c}\mathrm{R} \\
\text { Square } \\
\text { Change }\end{array}$ & \begin{tabular}{|c|}
$\mathrm{F}$ \\
Change
\end{tabular} & df1 & $\mathrm{df2}$ & $\begin{array}{c}\text { Sig. F } \\
\text { Change }\end{array}$ \\
\hline 1 & $.237^{2}$ & .056 & .046 & 486 & .056 & 5.318 & & 85 & .023 \\
\hline 2 & $.351^{\mathrm{t}}$ & .123 & 103 & .471 & .067 & 6.720 & & 85 & .01 \\
\hline
\end{tabular}

a. Predictors: (Constant), item 47

b. Predictors: (Constant), item47, Item47sqrt 


\section{Coefficients $^{\mathrm{a}}$}

\begin{tabular}{|l|r|r|r|r|r|}
\hline \multirow{2}{*}{ Model } & \multicolumn{2}{|c|}{ Unstandardized Coefficients } & \multicolumn{1}{c|}{$\begin{array}{c}\text { Standardized } \\
\text { Coefficients }\end{array}$} & \multirow{2}{*}{ Sig. } \\
\cline { 2 - 4 } & \multicolumn{1}{|c|}{$\mathrm{B}$} & \multicolumn{1}{c|}{ Std. Error } & \multicolumn{1}{c|}{ Beta } & & \\
\hline (Constant) & 1.806 & .171 & & 10.533 & .000 \\
item47 & -.092 & .040 & -.237 & -2.306 & .023 \\
(Constant) & 1.022 & .345 & & 2.958 & .004 \\
2 item47 & .507 & .234 & 1.314 & 2.166 & .033 \\
Item47sqrt & -.090 & .035 & -1.573 & -2.592 & .011 \\
\hline
\end{tabular}

a. Dependent Variable: item19

\section{Legend:}

Item 19 - Have you ever been (online) harassed/bullied at school or in your social environment?

Item 47 - My parents are always ready to listen to me or help me.

All standardized coefficients of Beta $(B=-0,237 ; B=1,314$ and $B=-$ 1,573 ) are significant at $\mathrm{p}$ values $<0,05$ which gives a high consistency to our both models. Changing Beta coefficient's sign from + to - means that the effect is growing in the opposite direction, which demonstrates the curvilinear relationship between youth online bullying incidents and youth perceived parental support. The additional incremental predictive capacity of 6 percent, added by including the squared youth perceived parental support variable which is accounting for the band in the regression line, clearly prove that there is a dynamic relationship between youth online bullying incidents and youth perceived parental support.

This dynamic relationship demonstrates that extreme aspects (extremely reduced and extremely frequent bulling incidents) of youth reported bullying situations significantly is influenced by a imbalanced youth perceived parental support, while situating on the middle continuum between reduced and extremely frequent bulling incidents, meaning a normal online bulling incident situation is influenced by a balanced youth perceived parental support.

Thus, a balanced perceived parental support ensures youth not to engage in bulling behaviors in real environments and as well as in online environments.

Until now, we are not aware of any research proving this dynamic relationship between youth online bullying incidents and youth perceived parental support, thus, this study may help expanding the current body of knowledge on psychological reasons that stand behind bulling incidents. In some cases, youth extreme bulling reports could send some alarms to parents and other relevant figures in their lives that are connected through different social media platforms. 


\section{Conclusions and discussions}

Most benefits in eliminating bullying would bring change of mentality from an early age. This is done through a longer-term plan that takes into account the following:

1. Non-formal anti-bullying education methods, such as role-playing games, where children understand the stance of each part of the bullying action and become aware of the serious consequences that neglect can have.

2. Addressing the topic at a depth level during counseling and orientation classes.

3. The organization of free seminars and debates, meetings with psychologists or persons who have been part of the bullying phenomenon and who have managed to overcome the situation as an example of good practice.

4. Adult notification by an adult (teacher, director, professor, school counselor, school mediator, supervisor / parent) whenever an act of bullying is reported by a colleague.

We all want schools where collaboration, collegiality and friendship is a priority. In essence, when we are talking about school, we refer to the place where children acquire essential skills and develop the defining relationships for their future. It is necessary for the school to remain a safe and friendly environment where children acquire essential knowledge and skills and develop relationships that are defining their future as adults.

This research was financed by European Union, inside the project Keeping youth safe from Cyberbullying, ID 2016-3-TR01-KA205-036619.

\section{References:}

Floros, G.D., Siomos, K.E., Fisoun, V., Dafouli, E., \& Geroukalis, D. (2013). Adolescent Online Cyberbullying in Greece: The Impact of Parental Online Security Practices, Bonding, and Online Impulsiveness. TOC, 83(6): 445-453.

Ross, S. W., \& Horner, R. H. (2009). Bully prevention in positive behavior support. Journal of Applied Behavior Analysis, 42(4), 747-759. http://doi.org/10.1901/jaba.2009.42-747.

Olweus, D. (1993). Bullying at school: What we know and what we can do. Cambridge, MA: Blackwell Publishers, Inc. 